\title{
Mechanism of Hyperreninemia in the Potassium-depleted Rat
}

\author{
STUART L. LiNAS, with the technical assistance of DAvid DickManN and \\ Patricia ARnold, Department of Medicine, Denver General Hospital and the \\ University of Colorado Health Sciences Center, Denver, Colorado 80262
}

A B S T R A C T Although dietary potassium deficiency (KD) results in an increase in plasma renin activity (PRA), the mechanism of this effect has not been elucidated. In the present study, isolated kidneys from normal rats or from rats made $\mathrm{KD}$ by diet were perfused at constant pressure $(120 \mathrm{~mm} \mathrm{Hg})$ with a KrebsRinger-bicarbonate medium containing albumin. KD led to an increase in PRA (3.6 vs. $1.1 \mathrm{ng}$ angiotensin I $\mathrm{ml}$ per h, $P<0.01$ ), which was associated with a decrease in macula densa (MD) fluid delivery as estimated by urine flow (70 vs. $166 \mu \mathrm{l} / \mathrm{min}$ per $\mathrm{g}, P<0.005$ ), and an increase in renal vascular resistance (RVR) as perfusion flow rate was decreased from 34 to $24 \mathrm{ml} / \mathrm{min}$ per $g, P<0.005$. The increase in PRA was independent of the MD because PRA could not be suppressed when macula densa delivery was increased by perfusing KD kidneys with hypooncotic albumin. Moreover, when kidneys were made nonfiltering by perfusing with hyperoncotic albumin, PRA remained increased in $\mathrm{KD}$ kidneys (8.1 vs. $3.5 \mathrm{ng}$ angiotensin $\mathrm{I} \mathrm{ml}$ per $\mathrm{h}, P$ $<0.01)$ despite the absence of MD delivery. Because the increase in PRA in both filtering and nonfiltering KD kidneys was associated with an increase in RVR, filtering and nonfiltering kidneys were perfused with the vasodilator papaverine. Despite lower tissue $K$ levels in KD kidneys (278 vs. $357 \mu \mathrm{eq} / \mathrm{g}, P<0.01$ ), RVR and PRA were normalized in both filtering and nonfiltering KD kidneys perfused with papaverine. In conclusion, PRA is increased in the KD isolated perfused kidney. This increase occurs independently of both the MD and of tissue $\mathrm{K}$ levels and is mediated by the renal vascular receptor.

Portions of this work were presented at the 13th Annual Meeting of the American Society of Nephrology, Washington, D. C., November 23-25, 1980, and appeared in abstract form in the Abstracts of the American Society of Nephrology 13, 1980 and in: 1980. Clin. Res. 28: 454A. (Abstr.)

Received for publication 27 October 1980 and in revised form 30 March 1981 .

\section{INTRODUCTION}

Chronic $\mathrm{K}$ deficiency results in an increase in plasma renin activity $(1,2)$. Although the mechanism of the increase in renin activity has not been elucidated, it is known to occur independently of the changes in sodium balance that may accompany $\mathrm{K}$ depletion $(1,2)$. There are, however, four alternative mechanisms whereby potassium depletion could influence the control of renin release (3). These include: $(a)$ a change in renal vascular tone (baroreceptor), $(b)$ a change in sodium delivery to the macula densa, $(c)$ an increase in renal sympathetic nerve activity, $(d)$ a direct effect by hypokalemia on the juxtaglomerular renin producing cells.

Whereas acute increases in sèrum $\mathrm{K}$ in $\mathrm{K}$-replete animals have been postulated to lower renin levels by a macula densa mechanism $(4,5)$, few studies have been performed on the chronically potassium-depleted animal. In this regard, $\mathrm{K}$ deficiency could alter renin activity by any one of several mechanisms. The renal vascular receptor mechanism is tenable because $\mathrm{K}$ deficiency has been shown to decrease renal blood flow $(6,7)$. A macula densa-mediated mechanism is also possible because $K$ deficiency has been shown to cause a decrease in fluid delivery out of the proximal tubule (8). Finally, although studies utilizing the kidney slice technique have failed to demonstrate an increase in renin production when slices are incubated with hypokalemic solutions $(9,10)$, the possibility that cellular $\mathrm{K}$ depletion per se rather than hypokalemia may be a direct stimulus for increased renin production has not been previously considered.

One of the difficulties encountered in studying the mechanism of renin release in the intact animal has been that many experimental maneuvers affect more than one variable that could alter renin production. The recent development of two techniques has provided the opportunity to control many of the variables known to influence renin production by the kidney. 
The nonfiltering kidney developed by Blaine et al. $(11,12)$ provided a novel approach to this problem. With this model, the renal vascular receptor is isolated from the macula densa because distal nephron fluid delivery is abolished and from the effects of circulating epinephrine by prior adrenalectomy and from renal nerves by prior renal denervation. The isolated perfused kidney has provided a second technique by which many of the factors known to affect renin release can be controlled. By perfusing the kidney outside the animal, renin release can be studied in the absence of renal nerves and in the absence of other circulating factors (such as catecholamines) that are known to directly increase renin levels $(10,13)$. In addition, fluid delivery to the macula densa can be maneuvered by altering the colloid concentration of the perfusion medium. By perfusing with hyperoncotic albumin solutions, the kidney can be made nonfiltering, and the renal vascular receptor can be isolated from the macula densa in the absence of ureteral obstruction as occurs in the in situ nonfiltering kidney of Blaine et al. $(11,12)$.

The purpose of the present study was to determine whether renin secretion was increased in the perfused kidneys of K-deficient rats and to determine the mechanism of the increased renin secretion. The results indicate that the mechanism of hyperreninemia in the perfused kidney of K-deficient rats was mediated by the renal vascular receptor.

\section{METHODS}

Studies were performed in male Sprague-Dawley rats weighing between 200 and $220 \mathrm{~g}$ at the initiation of the study. Animals were fed either a K-deficient diet (ICN Nutritional Biochemicals, Cleveland, Ohio) supplemented with magnesium (K-deplete group) or a diet of normal K content (K-replete group). The diet of normal $K$ content was prepared by supplementing the deficient diet with a combination of neutral $\mathrm{K}$ salts. The final compositions of the diets in millimoles per kilogram were as follows: $(a) \mathrm{K}$ deplete: $\mathrm{Na} 150, \mathrm{~K} 4, \mathrm{Cl} 620$, calcium 118, magnesium 165, phosphorus 59; (b) K replete: $\mathrm{Na} 160, \mathrm{~K} 210, \mathrm{Cl} 740$, calcium 105, magnesium 169, phosphorus 178. Water and food intake were allowed ad lib. After 14-18 d the animals were then studied according to one of the following experimental protocols.

\section{Effect of dietary $K$ restriction on plasma $K$ and on plasma renin activity in the intact rat}

In order to assess the effect of a decrease in the dietary intake of $\mathrm{K}$ on the circulating level of renin activity, plasma $\mathrm{K}$ and plasma renin activity were measured in rats on a normal $\mathrm{K}$ diet $(n=14)$ and in rats on a K-deficient diet $(n=14)$. In these animals blood was obtained by either aortic puncture after pentobarbital anesthesia or as free flowing blood issuing from the trunk of guillotined animals. Blood was collected in chilled tubes containing sodium EDTA, and samples were centrifuged within $15 \mathrm{~min}$ at $0^{\circ} \mathrm{C}$. Portions of plasma obtained from anesthetized animals were analyzed for $\mathrm{K}$ whereas the remaining plasma was stored at $-20^{\circ} \mathrm{C}$ and subsequently assayed for renin activity.

\section{Isolated perfused kidney studies}

Perfusion of the kidney was carried out according to the description of Nishiitsutsuji-Uwo et al. (14) as modified by Little and Cohen (15).

Perfusion apparatus. The perfusion apparatus described by Little and Cohen (15) and modified by Merkens et al. (16) were used in all perfusions. Several modifications of the circuit were made. Perfusate was circulated by two ColeParmer Masterflex pulsatile pumps (Cole-Parmer Instrument Co., Chicago, Ill.), one on the arterial side of the circulation, the other between the venous outflow and the membrane oxygenator. A $1.2-\mu \mathrm{m}$ pore size filter (RATF 04700 ; Millipore Corp., Bedford, Mass.) and prefilter (AP 25 04200) were placed in-line between the venous pump and membrane oxygenator. Arterial perfusate flow rate was determined by a tachometer (model 7598; Cole-Parmer Instrument Co.) attached to the pump head (model 7104; Cole-Parmer Instrument Co.). Arterial perfusion pressure was monitored with a pressure transducer (model 4-329-I; Bell \& Howell Co., CEC Div., Pasadena, Calif.) connected to a Gilson chart recorder (Gilson Medical Electronics, Inc., Middleton, Wis.). Mean arterial pressure distal to the tip of the cannula (19 gauge thinwalled needle cut to $2 \mathrm{~cm}$ in length) was maintained at $120 \mathrm{~mm} \mathrm{Hg}$ by varying perfusate flow rate. A thermistor probe (model YSI-416; Yellow Springs Instrument Co. Yellow Springs, Ohio) in the arterial reservoir-monitored perfusate temperature $\left(37-38^{\circ} \mathrm{C}\right)$. Perfusate $\mathrm{pH}$ was continuously monitored by a combination pH electrode (model 190300; Orion Research Inc., Cambridge, Mass.) inserted by a second port in the arterial reservoir. A silicone rubber tubing gas exchanger described by Hamilton et al. (17) was utilized as the membrane oxygenator. With this gas exchanger, the "arterial" oxygen tension of the perfusate was maintained between 375 and $450 \mathrm{~mm} \mathrm{Hg}$.

Perfusion medium. For each perfusion, $150 \mathrm{ml}$ of a KrebsRinger bicarbonate solution that contained albumin, urea, and inulin was used. The albumin was fraction $\mathrm{V}$ bovine albumin powder (Miles Laboratories, Inc., Elkhart, Ind.) which was made up as a $5 \%$ solution in deionized water and then concentrated to $15 \%$ over $24 \mathrm{~h}$ by ultrafiltration using a hollow fiber cartridge (model HIP10; Amicon Corp., Scientific Sys. Div., Lexington, Mass.). Portions of the concentrated albumin solution were stored at $-20^{\circ} \mathrm{C}$ and then were passed through a $0.8-\mu \mathrm{m}$ filter (model AATF 04700; Millipore Corp.) before being diluted by Krebs-Ringer bicarbonate solution for use. The final composition expressed in millimolar, unless otherwise noted, of the perfusion medium was sodium 140 , potassium 2.5-5.0, calcium 1.2 , magnesium 1 , chloride 105 , bicarbonate 25 , sulfate 1 , phosphate 2 , urea 7 , albumin $60 \mathrm{mg} / \mathrm{ml}$, glucose 5 , and $\mathrm{L}(+)$ lactic acid 5 (lot L1750; Sigma Chemical Co., St. Louis, Mo.). The perfusion medium was filtered through a $0.22-\mu \mathrm{m}$ filter (model GSTF 04700; Millipore Corp.) while introducing it into the steam-sterilized perfusion circuit where it was recirculated through the membrane gas exchanger and warmed to $37^{\circ} \mathrm{C}$.

The pH was adjusted to 7.35 with $\mathrm{Na}_{2} \mathrm{CO}_{3}$ and the solution gased with $5 \% \mathrm{CO}_{2}, 95 \% \mathrm{O}_{2}$. After the start of the perfusion, (hydroxy $\left[{ }^{14} \mathrm{C}\right]$ methyl)inulin (Amersham Corp., Arlington Heights, Ill.) was added to the venous reservoir.

Perfusion procedure. For all perfusions, kidneys were taken from animals on the experimental K-deficient diet or from animals on the control $\mathrm{K}$ diet. Anesthesia was pentobarbital $60 \mathrm{mg} / \mathrm{kg}$. In order to cannulate the ureter, 100 $\mathrm{mg}$ of mannitol was injected into the left femoral vein. The peritoneal cavity was opened, and the right ureter was cannulated with a $3-\mathrm{cm}$ length of PE 10 tubing. The right 
kidney was dissected free, the right adrenal gland excised, and the right adrenal artery was ligated near its origin from the renal artery. The right renal artery was cannulated in situ through the superior mesenteric artery as described by Nishiitsutsuji-Uwo et al. (14). Renal arterial perfusion was not interrupted at any time. The renal vein was not cannulated. The kidney was placed in the perfusion chamber over 60-90 s and perfused with a pulsatile pump at a constant mean arterial perfusion pressure (distal to the tip of the arterial cannula) of $120 \mathrm{~mm} \mathrm{Hg}$. After allowing $15 \mathrm{~min}$ for the kidney to equilibrate, perfusion flow rate was recorded, and a 3-ml perfusion sample was obtained. Three 15-min urine collections and perfusion samples were then obtained. Perfusion flow rates were determined at 5-min intervals during each urine collection, and the mean value of these determinations was used for subsequent comparisons. The total duration of each experiment was $60 \mathrm{~min}$. At the conclusion of each perfusion, the volume of perfusate remaining in the circuit was determined. Urine volume was determined by weighing the tared test tubes into which the urine dropped from the ureteral catheter. Perfusion samples were placed in a test tube for subsequent determination of sodium, potassium, and $\left[{ }^{14} \mathrm{C}\right]-$ inulin or in EDTA for determination of renin activity. Urine and perfusate samples were stored at $-20^{\circ} \mathrm{C}$ within $60 \mathrm{~min}$ of collection. During the 15-min equilibration period the left kidney was removed, sectioned, and after excess moisture was removed, the kidney was placed in a tared crucible, and its weight was determined. The perfused kidney was treated in a similar way at the conclusion of each experiment. The water content of each kidney was assumed to be the loss of weight after drying the kidneys to constant weight. In some studies the $\mathrm{K}$ content of control and experimental kidneys was determined.

The following experimental studies were undertaken.

\section{Group $I$, the effect of chronic $K$ depletion on the isolated perfused kidney (IPK) ${ }^{1}$}

Chronic $K$ depletion. In order to determine the effect of chronic K depletion on the function of the IPK, (7) kidneys from control animals and (9) kidneys from K-deficient animals were perfused. While control animals were perfused with 5 $\mathrm{mM} \mathrm{K}$, K-deficient animals were perfused with $2.5 \mathrm{mM} \mathrm{K}$ to approximate plasma $\mathrm{K}$ levels in K-deficient animals.

Because animals on a K-deficient diet ate less food (212 vs. $273 \mathrm{~g} / 14 \mathrm{~d}$ ) and gained less weight (48.9 vs. $68.9 \mathrm{~g} / 14 \mathrm{~d}$ ) than did animals on a K-replete diet, studies were performed in six animals maintained on a K-replete diet, but whose daily food intake was limited to that of pair-fed animals on a Kdeficient diet.

Acute changes in perfusate $K$ concentration. In order to determine if the increase in renin levels that were found in $\mathrm{K}$ deficient kidneys was the result of perfusing these kidneys with a lower $K$ concentration, kidneys from control animals were perfused with either $5 \mathrm{mM} \mathrm{K}(n=6)$ or $2.5 \mathrm{mM} \mathrm{K}(n=5)$ whereas kidneys from K-deplete animals were perfused with 5 $\mathrm{mM} \mathrm{K}(n=5)$ or $2.5 \mathrm{mM} \mathrm{K}(n=5)$. Because perfusing normal kidneys with hypokalemic solutions did not increase renin levels, and because perfusing K-deplete kidneys with normokalemic solutions did not decrease renin levels, all subsequent studies were performed with $K$ concentrations that approximated those found in intact rats, i.e., $5 \mathrm{mM} \mathrm{K}$ for control kidneys and $2.5 \mathrm{mM} \mathrm{K}$ for K-deplete kidneys.

\section{Group II, the role of the macula densa in the hyperreninemia of $K$ depletion}

Increased macula densa delivery. To determine if the decrease (vide infra) in macula densa fluid delivery could account for the increase in renin levels in K-deficient kidneys, studies were performed in which fluid delivery was altered by adjusting the albumin concentration of the perfusate. Because changes in albumin concentration affect ionized calcium levels and because calcium has been shown to alter renin production in the IPK (18), the concentration of ionized calcium was kept constant at $1.2 \mathrm{mM}$. Urine flow was increased by perfusing both control kidneys $(n=8)$ and K-deficient kidneys $(n=9)$ with a $20-\mathrm{mg} / \mathrm{ml}$ albumin solution.

Decreased macula densa delivery. To eliminate a role for the macula densa, kidneys (six control, seven K-deficient) were made nonfiltering by perfusing with hyperoncotic albumin solutions $(120 \mathrm{mg} / \mathrm{ml})$. This methodology assures that any changes in renin production occur independently of the macula densa because there is no fluid delivery to the macula densa. The absence of filtration was determined on the basis of: $(a)$ the total absence of urine flow; $(b)$ the failure of Lissamine green to appear in the renal tubules after injection into the perfusion circuit just proximal to the arterial cannula $(11,12) ;(c)$ as opposed to filtering kidneys, perfusate $\left[{ }^{14} \mathrm{C}\right]$ inulin levels remained unchanged over the $60 \mathrm{~min}$ of the study (19).

\section{Group III, the role of the renal vascular receptor}

Filtering kidneys. In order to determine if the decrease in renin levels from K-deficient kidneys was caused by the changes observed in renal hemodynamics, filtering kidneys were perfused with the arteriolar vasodilator papaverine (final concentration $0.39 \mathrm{mM}$, Eli Lilly Co., Indianapolis, Ind.). For these studies papaverine was added to the perfusion medium before its addition to the circuit. Three groups of animals were studied: ( $a$ ) control kidneys plus papaverine $(n=6) ;(b) \mathrm{K}$ deficient kidneys $(n=6) ;(c)$ K-deficient kidneys plus papaverine $(n=6)$.

Nonfiltering kidneys. To confirm that the results obtained with papaverine in filtering kidneys were caused solely by changes in renal hemodynamics, papaverine was added to nonfiltering kidneys in which the renal vascular receptor was isolated from the macula densa $(11,12)$. The three following groups of animals were studied: $(a)$ nonfiltering control kidneys plus papaverine $(n=6)$; $(b)$ nonfiltering K-deficient kidneys $(n=6)$; (c) nonfiltering K-deficient kidneys plus papaverine $(n=7)$.

Because papaverine has been shown to have a direct effect on in vitro renin production that is independent of the renal vascular receptor (20), a final group of perfusions were performed to determine whether papaverine prevented a nonvascular receptor stimulus for renin production in the perfused kidney. For these studies, control kidneys were made nonfiltering, and a macula densa stimulus to renin production was studied in the presence $(n=6)$ and absence of papaverine $(n=6)$.

Analytical methods. Sodium and potassium were measured with an IL 343 Flame Photometer (Instrumentation Laboratory, Inc., Lexington, Mass.). Renal tissue $\mathrm{K}$ was determined by nitric acid digestion. After drying the kidney to constant weight $\left(130^{\circ} \mathrm{C}\right.$ for $\left.72 \mathrm{~h}\right)$, the samples were ground to a fine powder and were digested by boiling in $1 \mathrm{ml}$ of nitric acid for $4 \mathrm{~h}$. The resulting clear liquid was diluted to $25 \mathrm{ml}$ with deionized water, and the $K$ content was then determined. $\left[{ }^{14} \mathrm{C}\right]$ inulin was counted in a Beckman LS 100 C liquid scintillation counter (Beckman Instruments Inc., Fullerton, Calif.). Ionized calcium was determined by an Orion Ionized Calcium Analyzer, Spacestat 70 (Orion Research Inc.). Albumin was determined by electrophoresis (21). Plasma renin activity was determined by radioimmuno- 
assay (22). For perfusate renin analysis, renin-free plasma from bilaterally nephrectomized dogs was collected by the method of Fray (23) and used for renin substrate. $25 \mu \mathrm{l}$ of the perfusate was added to $100 \mu \mathrm{l}$ of this plasma, and perfusate renin activity was determined by radioimmunoassay as previously noted (22).

\section{Calculations}

The urinary clearance of $\left[{ }^{14} \mathrm{C}\right]$ inulin, sodium, and potassium were calculated from their respective urine and plasma concentration ratios. The clearance of $\left[{ }^{14} \mathrm{C}\right]$ inulin was used as a measure of glomerular filtration rate (GFR). Fractional excretion of filtered $\mathrm{Na}$ and $\mathrm{K}$ was calculated as either $\mathrm{Na}$ or $\mathrm{K}$ clearance/GFR $\times 100$. Perfusion flow rate was determined by calibrating the tachometer attached to the arterial pump head immediately preceding each study. Urine flow rate was used to approximate distal nephron fluid delivery because in the absence of vasopressin, significant quantities of fluid are not reabsorbed in the distal nephron (24). The results of perfusate flow, glomerular filtration, and urine flow have been expressed per gram wet weight of the normal left kidney because the final wet weight of the perfused kidney varied with the albumin concentration of the perfusate. Because perfusion flow rate (PFR), GFR, and urinary sodium excretion were relatively constant over the $45 \mathrm{~min}$ of the study, clearance results are given as the mean of all collection periods.

In this preparation, renin is not degraded (23). Because the perfusion medium recirculates, renin from the perfused kidney represents cumulative production. Since the quantity of perfusate remaining after each experiment varied, renin values were corrected for this variable and are expressed as nanograms of angiotensin I generated per milliliter of perfusate per hour incubation in $100 \mathrm{ml}$ perfusate. Renin levels are those obtained after $1 \mathrm{~h}$ of perfusion.

Statistical analyses were performed using either the unpaired Student's $t$ test or one-way analysis of variance with Scheffe's test for multiple comparisons (25). A $P$ value of $<0.05$ was considered significant. Data are expressed as the mean \pm SEM.

\section{RESULTS}

\section{Effect of dietary $K$ restriction on plasma $K$ and on plasma renin activity in the intact rat}

After 2 wk of dietary $\mathrm{K}$ deficiency, plasma potassium was reduced from $3.8 \pm 0.1$ to $2.44 \pm 0.1 \mathrm{meq} / \mathrm{liter}, P$ $<0.001$, and plasma renin activity was increased from $12.8 \pm 1.5$ to $26.3 \pm 3.6 \mathrm{ng} \mathrm{AI} / \mathrm{ml}$ per $\mathrm{h}, P<0.005$ in anesthetized animals. Although the absolute renin levels were higher in anesthetized animals, renin levels were also increased in guillotined animals ( $1.9 \pm 0.4$ to $5.2 \pm 0.6 \mathrm{ng} \mathrm{AI} / \mathrm{ml}$ per $\mathrm{h}, P<0.005)$, thereby demonstrating the fact that the hyperreninemia of $\mathrm{K}$ deficiency is not simply an artefact of pentobarbital anesthesia.

\footnotetext{
${ }^{1}$ Abbreviations used in this paper: AI, angiotensin I; GFR, glomerular filtration rate; IPK, isolated perfused kidney; PFR, perfusion flow rate; UFR, urine flow rate.
}

\section{Isolated perfused kidney studies}

\section{GROUP I. THE EFFECT OF CHRONIC K DEPLETION ON THE IPK}

A. Chronic $K$ depletion. Table I demonstrates the effect of a K-deficient diet on the function of the IPK. Potassium depletion markedly affects renal function. Renin levels were increased from $1.13 \pm 0.22$ to $3.58 \pm 0.62$ $\mathrm{ng} \mathrm{AI} / \mathrm{ml}$ per $\mathrm{h}, P<0.01$. This increase in renin levels was associated with differences in perfusate and renal tissue $\mathrm{K}$ levels. In addition, in K-deficient kidneys, there was a decrease in distal nephron fluid delivery as reflected by urine flow rate (UFR) $(166 \pm 22$ in control vs. $70 \pm 14 \mu \mathrm{l} / \mathrm{min}$ per $\mathrm{g}$ in $\mathrm{K}$-deficient kidneys, $P<0.005)$. Moreover, there was also a decrease in perfusion flow rate $(34.0 \pm 2.1$ to $24.3 \pm 1.8 \mathrm{ml} / \mathrm{min}$ per $\mathrm{g}$, $P<0.005)$ reflecting an increase in renal vascular resistance in K-deficient kidneys. Furthermore, although rats maintained on the K-deficient diet ate less than rats maintained on the control diet, the hyperreninemia of $\mathrm{K}$ depletion was not the consequence of a decrease in food intake in K-deplete animals because renal function was unaltered in animals maintained on a K-replete diet whose food intake was limited to that of pair animals on the K-deficient diet: renin $1.02 \pm 0.06 \mathrm{ng} \mathrm{AI} / \mathrm{ml}$ per h; UFR $143 \pm 13 \mu \mathrm{l} / \mathrm{min}$ per g; PFR $31.8 \pm 1.3 \mathrm{ml} / \mathrm{min}$ per g; GFR $567 \pm 40 \mu \mathrm{l} / \mathrm{min}$ per $g$. Because the IPK is denervated, these results demonstrate the fact that the hyperreninemia of $\mathrm{K}$ deficiency can occur independent of changes in either systemic hemodynamics or in renal sympathetic nerve activity. On the other hand, because a decrease in plasma or tissue $\mathrm{K}$ as well as a decrease in macula densa delivery and alterations in the renal vascular receptor have all been demonstrated to affect renin release, further studies were performed to elucidate the mechanism of hyperreninemia after $\mathrm{K}$ deficiency.

$B$. Acute changes in perfusate $K$ concentration. In order to confirm that $\mathrm{K}$ depletion rather than acute hypokalemia was the cause of increased renin levels from K-deficient animals, control kidneys were perfused with hypokalemic solution while K-deplete kidneys were perfused with normokalemic solution. The results of these perfusions are shown in Table II. Despite perfusate $\mathrm{K}$ levels which were comparable with those of chronically K-deficient kidneys, normal kidneys perfused with hypokalemic solutions did not have elevated renin levels. In addition, acute hypokalemia did not result in any changes in either UFR, GFR, or in PFR. Moreover, perfusing K-deplete kidneys with $5 \mathrm{mM} \mathrm{K}$ resulted in comparable changes in renin, hemodynamics, and tissue $K$, as did perfusing K-deplete kidneys with $2.5 \mathrm{mM} \mathrm{K}$. Thus the hyperreninemia of $\mathrm{K}$ deficiency is the consequence of $K$ depletion rather than of low perfusate $K$ concentration per se. 
TABLE I

The Effect of Chronic K Depletion on the Function of the Perfused Kidney

\begin{tabular}{|c|c|c|c|c|c|c|c|c|c|}
\hline & UFR & GFR & PFR & $\mathrm{U}_{\mathrm{Nav}}$ & $\% \mathrm{~T}_{\mathrm{Na}}$ & $\% \mathrm{~T}_{k}$ & $\mathbf{P}_{\mathbf{k}}$ & $\begin{array}{l}\text { Control kidney } \\
\text { Tissue K }\end{array}$ & PRA \\
\hline & \multicolumn{2}{|c|}{$\mu l / \min / g$} & $\mathrm{ml} / \mathrm{min} / \mathrm{g}$ & Meq/min/g & & & mEq/liter & $\mu e q / g d r y w t$ & $n g A I / m l$ \\
\hline $\begin{array}{l}\text { Normal K diet, } \\
n=7 \\
\text { K-deficient }\end{array}$ & $166 \pm 22$ & $532 \pm 60$ & $34.0 \pm 2.1$ & $13.8 \pm 1.9$ & $84 \pm 0.6$ & $30 \pm 5.0$ & $4.23 \pm 0.2$ & $335.1 \pm 4.2$ & $1.13 \pm 0.22$ \\
\hline diet, $n=9$ & $70 \pm 14$ & $304 \pm 41$ & $24.3 \pm 1.8$ & $8.1 \pm 1.1$ & $87 \pm 1$ & $74 \pm 2.2$ & $2.58 \pm 0.06$ & $287.0 \pm 7.8$ & $3.58 \pm 0.62$ \\
\hline$P$ values & 0.005 & 0.01 & 0.005 & 0.02 & NS & 0.001 & 0.001 & 0.001 & 0.01 \\
\hline
\end{tabular}

$U_{\mathrm{Nav}}$, urinary sodium excretion; $\% \mathrm{~T}_{\mathrm{Na}}$, percentage of filtered $\mathrm{Na}$ reabsorbed; $\% \mathrm{~T}_{\mathrm{K}}$, percentage of filtered $\mathrm{K}$ reabsorbed; $\mathrm{P}_{\mathrm{K}}$, perfusate potassium; PRA, perfusate renin activity.

\section{GROUP II, THE ROLE OF THE MACULA DENSA}

A. Increased macula densa delivery. In order to determine if the decrease in distal nephron fluid delivery contributed to the increase in renin levels of $\mathrm{K}$-deficient kidneys, distal delivery was enhanced by decreasing the albumin concentration of the perfusate. Table III depicts the results of these studies. Perfusing with hypooncotic albumin led to an increase in urine flow and in urinary sodium excretion in both control and K-deficient kidneys. Despite this increase in urine flow, renin levels were still increased in $\mathrm{K}$ deficient kidneys $(3.10 \pm 0.4$ vs. $0.63 \pm 0.1 \mathrm{ng} \mathrm{AI} / \mathrm{ml}$ per $h, P<0.001$ ). Although not statistically significant, UFR and urinary sodium excretion were less in the K-deficient kidneys. When compared, therefore, with control kidneys with less distal delivery (Table I, normal $\mathbf{K}$ diet) renin levels were still significantly increased in K-deficient kidneys ( $3.10 \pm 0.4$ vs. $1.13 \pm 0.22$ ng $\mathrm{AI} / \mathrm{ml}$ per $\mathrm{h}, P<0.05$ ).

$B$. Decreased macula densa delivery. In order to define further the role of the macula densa, fluid delivery to the macula densa was eliminated by perfusing with hyperoncotic albumin solutions. The results of these studies are shown in Table IV. In the absence of macula densa delivery, renin levels continued to be greater in K-deficient kidneys. Moreover, K-deficient kidneys continued to be vasoconstricted as compared with control kidneys as PFR was reduced in these kidneys from $40 \pm 2.6$ to $31 \pm 1.4 \mathrm{ml} / \mathrm{min}$ per $\mathrm{g}$, $P<0.01$. Because the renin levels of $\mathrm{K}$-deficient kidneys was greater than control kidneys even in the absence of macula densa fluid delivery, the mechanism of hyperreninemia occurred independently of changes in macula densa fluid delivery.

TABLE II

The Effect of Perfusing Control Kidneys with Hypokalemic Solutions and K-deplete Kidneys with Normokalemic Solutions

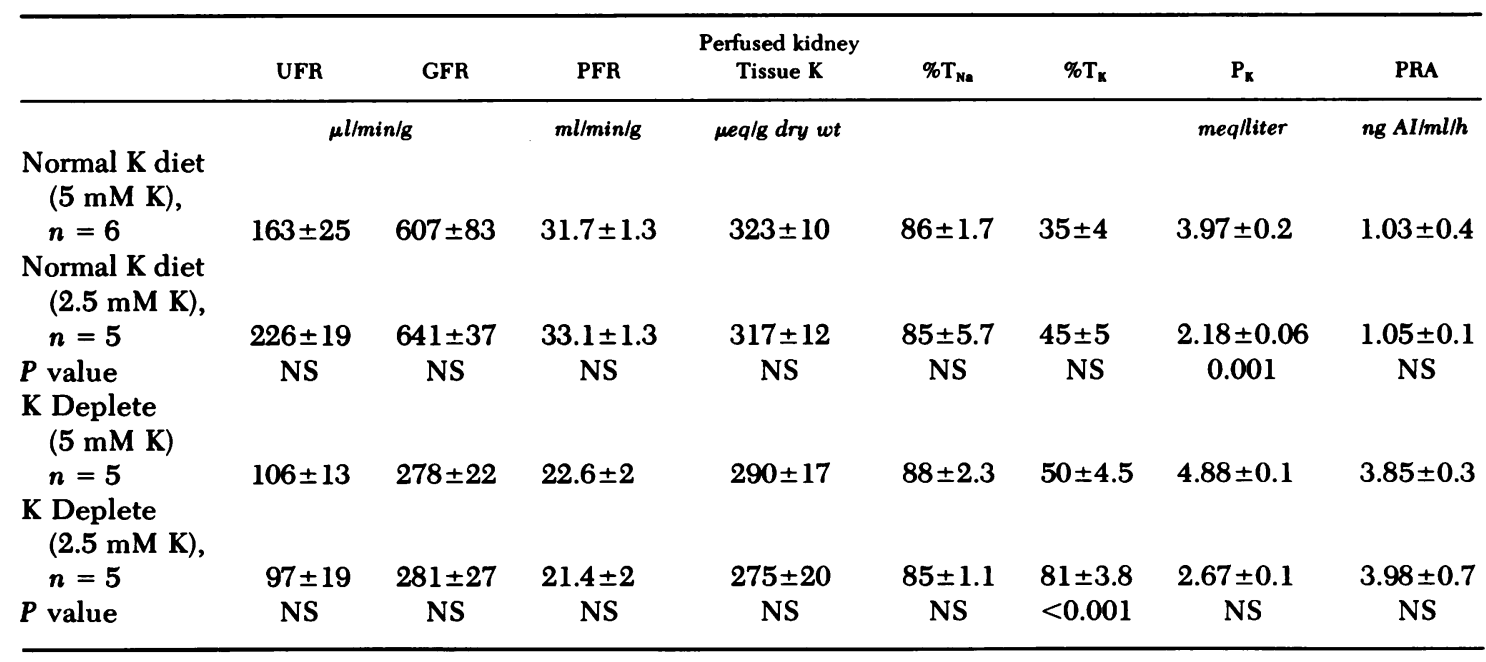

$\% \mathrm{~T}_{\mathrm{Na}}$, percentage of filtered $\mathrm{Na}$ reabsorbed; $\% \mathrm{~T}_{K}$, percentage of filtered $\mathrm{K}$ reabsorbed; $\mathrm{P}_{\mathrm{K}}$, perfusate potassium; PRA, perfusate renin activity. 
TABLE III

The Effect of Increasing Distal Nephron Fluid Delivery

\begin{tabular}{lcccccc}
\hline & UFR & GFR & PFR & $\% \mathrm{~T}_{\mathrm{Na}}$ & U $_{\mathrm{Nav}}$ & PRA \\
\hline & \multicolumn{2}{c}{$\mu l / m i n / g$} & ml/min/g & & $\mu e q / m i n / g$ & $n g$ AI/ml/h \\
Normal K diet $(n=8)$ & $336 \pm 45$ & $744 \pm 65$ & $27.7 \pm 1.8$ & $77.5 \pm 2.4$ & $25.5 \pm 4.9$ & $0.63 \pm 0.1$ \\
K-deficient diet $(n=9)$ & $254 \pm 34$ & $447 \pm 37$ & $19.9 \pm 1.3$ & $75.4 \pm 1.7$ & $17.1 \pm 0.16$ & $3.10 \pm 0.4$ \\
$P$ value & $\mathrm{NS}$ & 0.005 & 0.005 & $\mathrm{NS}$ & $\mathrm{NS}$ & 0.001 \\
\hline
\end{tabular}

UFR, urine flow rate, GFR, glomerular filtration rate; PFR, perfusion flow rate; $\mathrm{U}_{\mathrm{Nav}}$, urinary sodium excretion; $\% \mathrm{~T}_{\mathrm{Na}}$, percentage of filtered $\mathrm{Na}$ reabsorbed; PRA, perfusate renin activity.

\section{GROUP III, THE ROLE OF THE RENAL VASCULAR RECEPTOR}

A. Filtering kidneys. Because an increase in renal vascular resistance may have mediated the increase in renin production in K-deficient kidneys, filtering kidneys were perfused with papaverine, a dilator of vascular smooth muscle. The results of these perfusions are depicted in Table V. The inclusion of papaverine in the perfusion medium had no effect on hemodynamics, tubular function, or renin levels of the control kidneys. On the other hand, papaverine caused marked changes in the K-deficient kidneys. Both perfusion flow rate and urine flow rate were increased, and these changes were associated with the normalization of renin levels. Although these results and those of group II studies would suggest a primary role for the renal vascular receptor, the possibility could not be excluded that the combination of vasodilatation plus increased macula densa fluid delivery resulted in the normalization of renin levels in K-deficient kidneys; further studies, therefore, were undertaken.

B. Nonfiltering kidneys. For this final group of studies the renal vascular receptor was isolated from the macula densa by rendering the kidneys nonfiltering. Moreover, the isolated renal vascular receptor was rendered nonfunctional by papaverine. The results of these studies are shown in Fig. 1. In the nonfiltering control kidney, papaverine had no effect on

TABLE IV

The Effect of $\mathrm{K}$ Depletion on the Nonfiltering Isolated Perfused Kidney

\begin{tabular}{ccc}
\hline & PFR & PRA \\
\hline & $m l / m i n / g$ & $n g$ Al $/ m l / h$ \\
Normal K diet, & & \\
$n=6$ & $40 \pm 2.6$ & $3.52 \pm 0.5$ \\
K-deficient diet, & & \\
$n=7$ & $31 \pm 1.4$ & $8.14 \pm 1.1$ \\
$P$ value & 0.01 & 0.01 \\
\hline
\end{tabular}

PRA, perfusate renin activity. either PFR or renin. On the other hand, papaverine caused a decrease in vascular tone in K-deficient kidneys as PFR increased from $30.5 \pm 1.3 \mathrm{ml} / \mathrm{min}$ per $\mathrm{g}$ in the absence of the vasodilator to $39.9 \pm 2.8 \mathrm{ml} /$ min per $g, P<0.01$ in the presence of papaverine. Moreover, the decrease in renal vascular tone in $\mathrm{K}$ deficient kidneys was accompanied by a decrease in renin levels in the $\mathrm{K}$-deficient kidneys to values observed in control kidneys. Table VI demonstrates that papaverine had no direct effect on renin production in the IPK because macula densa-mediated renin production was not altered by the drug. Thus in the K-deficient kidney, when the renal vascular receptor is isolated and neutralized with papaverine, renin production is identical to control kidneys.

\section{DISCUSSION}

In the present study we have systematically investigated the mechanism of hyperreninemia in K-depleted rats. Perfused kidneys from K-deficient animals had many of the same renal functional changes as have been described in the intact kidney of K-deficient rats. In this regard, perfused kidneys from K-deficient rats had a decrease in $\operatorname{GFR}(6,26)$ as well as a decrease in perfusate flow rate and an increase in renal vascular resistance $(6,7)$ when compared with K-replete kidneys. In addition to these alterations in renal functional parameters, renin levels were also increased in K-deficient kidneys. Because perfused kidneys of Kdeficient animals had increased renin levels and many of the same functional abnormalities as intact kidneys from K-deficient animals, the isolated kidney provided an ideal technique to evaluate the mechanism of hyperreninemia of $\mathrm{K}$ depletion.

In the absence of renal nerves, there were three mechanisms that may have mediated the hyperreninemia of $K$ depletion. In this regard, the renal vascular receptor could have been activated because $\mathrm{K}$ depletion led to an increase in renal vascular resistance. The macula densa could have mediated the increase in renin production because macula densa delivery was decreased in K-deficient kidneys. Finally, 
TABLE V

The Effect of Perfusing K-deficient Kidneys with Papaverine

\begin{tabular}{|c|c|c|c|c|c|c|c|c|}
\hline & UFR & GFR & PFR & $\mathrm{U}_{\mathrm{Nav}}$ & $\% \mathrm{~T}_{\mathrm{Na}}$ & $\% \mathrm{~T}_{k}$ & $\begin{array}{c}\text { Perfused } \\
\text { kidney tissue }\end{array}$ & PRA \\
\hline & \multicolumn{2}{|c|}{$\mu l / m i n / g$} & $\mathrm{ml} / \mathrm{min} / \mathrm{g}$ & $\mu e q / m i n / g$ & & & $\mu e q / g d r y$ wt & $n g \mathrm{AI} / \mathrm{ml} / \mathrm{h}$ \\
\hline $\begin{array}{l}\text { Normal K diet } \\
\text { plus papaverine, } \\
n=6\end{array}$ & $195 \pm 29$ & $595 \pm 52$ & $30.2 \pm 2.2$ & $13.7 \pm 2.8$ & $83.0 \pm 2.5$ & $49.0 \pm 2.7$ & $346.5 \pm 12.7$ & $0.59 \pm 0.12$ \\
\hline $\begin{array}{l}\text { K-deficient diet, } \\
\quad n=6\end{array}$ & $52 \pm 9.9$ & $270 \pm 36$ & $21.0 \pm 1.5$ & $3.8 \pm 1$ & $88.7 \pm 1.7$ & $74.0 \pm 4.4$ & $285.7 \pm 9.9$ & $3.1 \pm 0.70$ \\
\hline $\begin{array}{l}\text { K-deficient diet } \\
\text { plus papaverine, } \\
n=6\end{array}$ & $146 \pm 10$ & $377 \pm 31$ & $29.8 \pm 0.5$ & $13.8 \pm 1.4$ & $75.0 \pm 2.1$ & $80.7 \pm 3.8$ & $277.5 \pm 12.9$ & $0.60 \pm 0.23$ \\
\hline$P$ value: & & & & & & & & \\
\hline $\begin{array}{l}\text { Control vs. } \downarrow K \\
\downarrow K \text { vs. } \downarrow K \text { plus }\end{array}$ & 0.01 & 0.01 & 0.01 & 0.01 & NS & 0.01 & 0.01 & 0.01 \\
\hline $\begin{array}{c}\text { papaverine } \\
\text { Control vs. } \downarrow K\end{array}$ & 0.01 & 0.05 & 0.01 & 0.01 & 0.01 & NS & NS & 0.01 \\
\hline plus papaverine & NS & 0.01 & NS & NS & 0.05 & 0.01 & 0.01 & NS \\
\hline
\end{tabular}

$\mathrm{U}_{\mathrm{Nav}}$, urinary sodium excretion; $\% \mathrm{~T}_{\mathrm{Na}}$, percentage of filtered $\mathrm{Na}$ reabsorbed; $\% \mathrm{~T}_{\mathrm{K}}$, percentage of filtered $\mathrm{K}$ reabsorbed; $P_{K}$, perfusate potassium; PRA, perfusate renin activity.

a decrease in either perfusate or tissue $\mathrm{K}$ levels could have directly altered renin production by the juxtaglomerular apparatus. Studies were performed, therefore, that excluded both the macula densa and direct mechanisms.

Although it is probable that renal renin content, a major determinant of perfusate renin activity (27), was increased in K-deplete kidneys, two groups of studies exclude a direct effect of either hypokalemia or $\mathrm{K}$ depletion per se as the stimulus for renin release. In the first group of studies (Table II), renin levels were not increased in normal kidneys perfused with hypokalemic solutions and renin levels were not decreased in K-deplete kidneys perfused with normokalemic solutions. In the second group of studies (group III, Table V and Fig. 1), renin levels were normalized in K-deficient kidneys perfused with papaverine despite the fact that renal tissue $K$ levels were decreased in these K-deficient kidneys. The fact that renin levels could be normalized in kidneys that had a decrease in tissue $\mathrm{K}$ implies the lack of a direct effect of $\mathrm{K}$ depletion per se on either renal renin content or perfusate renin activity. In support of this observation in the perfused kidney, studies using kidney slices have also failed to demonstrate a direct effect of hypokalemia on renin production (10).

Although the increased renin levels could have been mediated by the macula densa because macula densa fluid delivery was decreased in the perfused kidneys of K-deficient rats (Table I), there are two groups of studies that clearly demonstrate the fact that the increase in renin levels occurred independently of the macula densa. In the first group of studies, albumin levels were decreased in the perfusate of K-deficient kidneys. By decreasing albumin levels in the perfusate, proximal nephron fluid reabsorption can be decreased (28), and distal nephron, hence macula densa, fluid delivery can be increased (group IIA, Table III). Despite a marked increase in macula densa
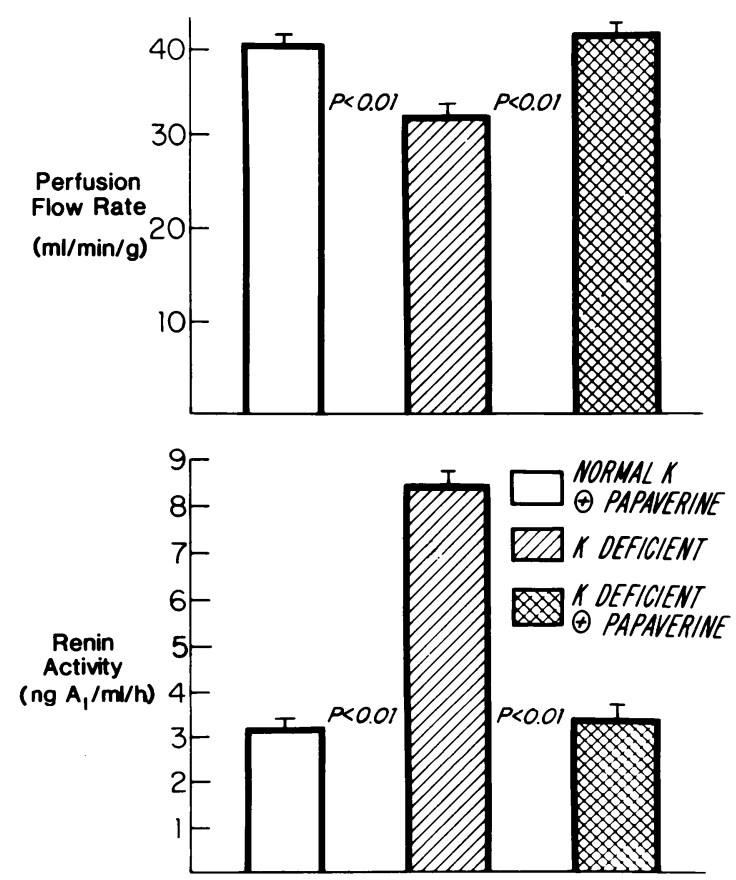

Figure 1 The effect of perfusing nonfiltering potassiumdepleted kidneys with the arteriolar vasodilator papaverine. 
TABLE VI

The Effect of Papaverine on Renin Production in the Nonfiltering K Replete Isolated Kidney

\begin{tabular}{lcccc}
\hline & \multicolumn{4}{c}{ Time } \\
\cline { 2 - 5 } & $15-30 \mathrm{~min}$ & $30-45 \mathrm{~min}$ & $45-60 \mathrm{~min}$ & $\begin{array}{c}\text { Cumulative } \\
60 \text {-min } \\
\text { production }\end{array}$ \\
\hline Renin production, $n \mathrm{AI} / \mathrm{ml} / \mathrm{h}$ & & & & \\
Control, no papaverine & $1.05 \pm 0.15$ & $0.82 \pm 0.27$ & $1.63 \pm 0.14$ & $3.33 \pm 0.38$ \\
Control, papaverine & $1.13 \pm 0.28$ & $1.02 \pm 0.15$ & $1.36 \pm 0.17$ & $3.60 \pm 0.53$ \\
$P$ value & $\mathrm{NS}$ & $\mathrm{NS}$ & $\mathrm{NS}$ & $\mathrm{NS}$ \\
\hline
\end{tabular}

Renin production is expressed as the amount of $\mathrm{AI}$ generated at the end of each 15-min period of perfusion minus the amount of AI generated at the beginning of the period. All samples were incubated for $1 \mathrm{~h}$ and are normalized to $100 \mathrm{ml}$ of perfusate.

fluid delivery in K-deficient kidneys, renin levels remained elevated.

Although these results do not support a macula densa mechanism, it should be noted that UFR is only a crude index of macula densa fluid delivery. Moreover, even in the presence of comparable macula densa delivery, it is possible that sodium transport at that segment of the nephron might differ in K-deficient and K-replete kidneys. Because the signal sensed by the macula densa has been postulated to be either an increase (29) or a decrease (30) in $\mathrm{Na}$ transport, further studies were performed in the nonfiltering perfused kidney in which the fluid delivery to the macula densa was eliminated, thereby assuring that any differences in renin production occur independently of the macula densa. In both the nonfiltering K-replete and K-deplete kidneys, group IIB, Table IV), renin levels were greater than in their filtering controls (Table I). In the absence of other factors known to alter renin release (in particular, changes in ionized calcium concentration [18]), it is likely that the decrease in macula densa delivery resulted in the increase in renin levels in both groups of nonfiltering kidneys. Despite the absence of macula densa delivery, renin levels were greater in the $\mathrm{K}$ deficient kidneys. These results confirm the fact that neither sodium delivery nor sodium transport at the macula densa were necessary for higher renin levels to occur in K-deficient kidneys. Because renin levels were greater in K-deficient kidneys at both extremes of macula densa fluid delivery, the increase in renin levels occurs independently of the macula densa.

In contrast to the absence of evidence supporting either a direct or a macula densa mechanism of renin release, there is substantial evidence to support a vascular mechanism. Thus, when either filtering or nonfiltering K-deplete kidneys were treated with papaverine, an arteriolar vasodilator, renal vascular resistance was decreased, and renin levels were identical to control kidneys (group III, Table V and Fig. 1). More- over, although in vitro studies have demonstrated a direct inhibitory effect of papaverine on renin production from renal slices (20), papaverine did not prevent the increase in renin production that was produced by a nonvascular stimulus to the perfused kidney (Table VI). Taken together, therefore, the data from the present study supports the conclusion that the increased renin production from the perfused kidney of the K-deplete rat is mediated by the renal vascular receptor.

Because perfusion pressure was held constant in these studies, the signal perceived by the renal vascular receptor was an increase in renal vascular resistance rather than a decrease in intraluminal pressure. Vasoconstriction in the absence of changes in intraluminal pressure is a well-known stimulus for renin release $(3,31)$. The cause of vasoconstriction in the perfused K-deficient kidney is not readily apparent. Although vasoconstrictors such as renal nerves, angiotensin II (32), and catecholamines (33), are not present in the isolated kidney, thromboxane $A_{2}$, a vasoconstrictor product of prostaglandin metabolism, has recently been reported to be increased in $\mathrm{K}$ deficient rats (34). Because the present study was not designed to investigate the mechanism of renal vasoconstriction during $\mathrm{K}$ depletion, further studies will be necessary to determine the roles of thromboxane and $\mathrm{K}$ depletion per se as mediators of the increased renal vascular resistance of $\mathrm{K}$ depletion.

In summary, the present study has conclusively shown that renin production is increased in perfused kidneys of K-deficient rats. The increase in renin is associated with an increase in renal vascular resistance and a decrease in both macula densa fluid delivery and in tissue $\mathrm{K}$ levels. Perfusing K-deficient kidneys with hypooncotic albumin increased urine flow rate to levels observed in control kidneys but did not decrease renin production. Nonfiltering Kdeficient kidneys produced more renin than non- 
filtering control kidneys. This increase in renin was associated with vasoconstriction, and both the hyperreninemia and vasoconstriction in K-deficient nonfiltering kidneys could be normalized with papaverine. In conclusion, the hyperreninemia of $\mathrm{K}$ depletion is mediated by the renal vascular receptor.

\section{ACKNOWLEDGMENTS}

The author thanks Dr. Tomas Berl, Robert W. Schrier, and Julius J. Cohen for their advice in the course of these studies. Mrs. Dee Simmons provided expert secretarial assistance.

This study was supported by a research grant from the National Institutes of Health AM 26156-02.

\section{REFERENCES}

1. Sealey, J. E., I. Clark, M. B. Bull, and J. H. Laragh. 1970. Potassium balance and the control of renin secretion. J. Clin. Invest. 49: 2119-2127.

2. Abbrecht, P., and A. Vander. 1970. Effects of chronic potassium deficiency on plasma renin activity. J. Clin. Invest. 49: 1510-1516.

3. Davis, J. O., and R. H. Freeman. 1976. Mechanisms regulating renin release. Physiol. Rev. 56: 1-56.

4. Vander, A. J. 1970. Direct effects of potassium on renin secretion and renal function. Am. J. Physiol. 219: 455-459.

5. Shade, R. E., J. O. Davis, J. A. Johnson, and R. T. Witty. 1972. Effects of renal arterial infusion of sodium and potassium on renin secretion in the dog. Circ. Res. 31: 719-727.

6. Abbrecht, P. 1969. Effects of potassium deficiency on renal function in the dog. J. Clin. Invest. 48: 432-442.

7. Abbrecht, P. 1972. Cardiovascular effects of chronic potassium deficiency in the dog. Am. J. Physiol. 223: 555-556.

8. Bank, N., and H. S. Aynedjian. 1964. A micropuncture study of the renal concentrating effect of potassium depletion. Am. J. Physiol. 206: 1347-1354.

9. Churchill, M. C., and P. C. Churchill. 1980. Separate and combined effects of ouabain and extracellular potassium on renin secretion from rat renal cortical slices. J. Physiol. 300: 105-114.

10. Aoi, W., W. B. Wade, O. R. Rosner, and M. H. Weinberger. 1974. Renin release by rat kidney slices in vitro: effects of cations and catecholamines. Am. J. Physiol. 227: $630-634$.

11. Blaine, E. H., J. O. Davis, and R. T. Witty. 1970. Renin release after hemorrhage and after suprarenal aortic constriction in dogs without sodium delivery to the macula densa. Circ. Res. 27: 1081-1089.

12. Blaine, E. H., J. O. Davis, and R. L. Prewitt. 1971. Evidence for a renal vascular receptor in control of renin secretion. Am. J. Physiol. 220: 1593-1597.

13. Michelakis, A. M., J. Caudle, and G. W. Liddle. 1969. In vitro stimulation of renin production by epinephrine, norepinephrine, and cyclic AMP. Proc. Soc. Exp. Biol. Med. 130: 748-753.

14. Nishiitsutsuji-Uwo, J. M., B. D. Ross, and H. A. Krebs. 1967. Metabolic activities of the isolated perfused rat kidney. Biochem. J. 103: 852-862.

15. Little, J. R., and J. J. Cohen. 1974. Effect of albumin concentration on function of isolated perfused rat kidney. Am. J. Physiol. 226: 512-517.

16. Merkens, L. S., J. J. Cohen, O. W. Peterson, M. J. Zamlauski, G. M. Gregg, and A. J. Black. 1978. Tissue $\mathrm{K}^{+}$loss from the perfused rat kidney: effects of lactate and albumin treatment. Am. J. Physiol. 235: F228-F233.

17. Hamilton, R. L., M. N. Berry, M. C. Williams, and E. M. Severinghaus. 1974. A simple and inexpensive membrane "lung" for small organ perfusion. J. Lipid Res. 15: $182-186$.

18. Fray, J. C. S. 1977. Stimulation of renin release in perfused kidney by low calcium and high magnesium. Am.J. Physiol. 232: F377-F382.

19. Maack, T. 1980. Physiological evaluation of the isolated perfused rat kidney. Am. J. Physiol. 238: F71-F78.

20. Lyons, H. J., and P. C. Churchill. 1979. The effect of papaverine on in vitro renin secretion. Proc. Soc. Exp. Biol. Med. 160: 237-240.

21. Kaplan, A., and J. Savory. 1965. Evaluation of cellulose acetate electrophoresis system for serum protein fractionation. Clin. Chem. 11: 937-942.

22. Stockigt, J. R., R. D. Collins, and E. P. Bigliere. 1971. Determination of plasma renin concentration by angiotensin I immunoassay. Circ. Res. 28(Suppl. 2): 175191.

23. Fray, J. C. S. 1976. Stretch receptor model for renin release with evidence from perfused rat kidney. Am. J. Physiol. 231: 936-944.

24. Seldin, D. W., and F. C. Rector. 1973. Evaluation of clearance methods for localization of site of action of diuretics. In Modern Diuretic Therapy in the Treatment of Cardiovascular and Renal Disease. A. F. Lant and G. M. Wilson, editors. Excerpta Medica, Amsterdam, The Netherlands. 97.

25. Remington, R. D., and M. A. Schork. 1970. Statistics with Applications to the Biological and Health Sciences. Prentice-Hall, Inc., Englewood Cliffs, N. J.

26. Brunner, F. P., F. C. Rector, Jr., and D. W. Seldin. 1966. The mechanism of the urinary concentrating defect in potassium depleted rats. Pfluegers Arch. Eur. J. Physiol. 290: 202-210.

27. Park, C. S., R. L. Malvin, R. D. Murray, and K. W. Cho. 1978. Renin secretion as a function of renal renin content in dogs. Am. J. Physiol. 234: F506-F509.

28. Gilbert, B. R., T. Maach, and E. E. Windhager. 1979. Microperfusion study of the effects of colloid osmotic pressure on proximal tubule fluid reabsorption in the isolated perfused rat kidney. Fed. Proc. 38: 1122A.

29. Thurau, K. 1964. Renal hemodynamics. Am. J. Med. 36: $698-719$.

30. Vander, A. J., and R. Miller. 1964. Control of renin secretion in the dog. Am. J. Physiol. 207: 537-545.

31. Vander, A. J. 1967. Control of renin release. Physiol. Rev. 47: 359-382.

32. Dávalos, M., N. S. Frega, B. Saker, and A. Leaf. 1978. Effect of exogenous and endogenous angiotensin II in the isolated perfused rat kidney. Am. J. Physiol. 235: F604-F610.

33. Besarab, A., P. Silva, L. Landsberg, and F. H. Epstein. 1977. Effect of catecholamines on tubular function in the isolated perfused rat kidney. Am. J. Physiol. 233: F39-F45.

34. Beck, N., and J. O. Shaw. 1981. Thromboxane $B_{2}$ and prostaglandin $\mathrm{E}_{2}$ in the $\mathrm{K} \pm$ depleted rat kidney. Am. J. Physiol. 240: F151-F157. 